\title{
Regional development of enterprises: concept of sustainable development and data mining
}

\author{
Nataliia Maksyshko ${ }^{1, *}$, Sergey Ivanov ${ }^{1}$, and Serhii Cheverda ${ }^{1}$ \\ ${ }^{1}$ Zaporizhzhia National University, Department of Economic Cybernetics, 66 Zhukovskogo Str., Zaporizhzhia, 69600, Ukraine
}

\begin{abstract}
Ukrainian enterprises are having a goal of get on with the concept of sustainable development. However, in the different regions of Ukraine there are various challenges, which needed to be considered in management of enterprises and organizations. Therefore important question is discovered about the main directions of developing enterprises, which will be relevant for a particular region. This study is highlighting statistic indicators, which characterizing the economic, social and environmental components of sustainable development of Ukrainian enterprises. On the basis of data about 1990-2019 years (2020 isn't used due to the impact of the pandemic, which significantly affected these parameters) cluster analysis of sustainable development enterprises of Ukraine by region is made. In the result of clustering regions were separated in three groups (clusters). Detailed analysis of the features of indicators of each cluster (group of regions) is made. On the basis of results of clustering recommendations about priority directions of increasing the level of sustainable development of Ukraine are discovered. Results of the study can be used in management of local enterprises and organizations in the certain regions to improve the level of achievement of sustainable development goals.
\end{abstract}

\section{Introduction}

In modern business conditions, enterprises face the processes of globalization, intensive changes that lead to uneven market development, uncertainty of the environment, inconsistencies in the implementation of the needs and interests of different market participants. It becomes obvious that achieving economic growth alone, even constant, is insufficient, as high rates of production can coexist with low efficiency of economic and social processes, become a threat to the environment. Therefore, it is important to ensure sustainable development of enterprises in the conditions of constant changes [1].

An important role in achieving sustainable development of enterprises is played by the evaluation of its indicators. This allows faster effective decisionmaking through the choice of appropriate criteria, methods, technologies, models, response mechanisms, interaction [2].

The formation of a system for assessing the sustainable development of Ukrainian enterprises is carried out taking into account the most problematic aspects of management, related to the functioning of ecosystems, ensuring environmental, economic and social needs of society. It should perform not only informational and control functions, but also reflect the desired changes and trends and timely direct efforts to achieve the goal.

Sustainable development has many dimensions, such as improving the social living conditions of the population, improvement of production infrastructure and other. Research in these areas has been carried out in many scientific works [3-4].

However, it is important to improve the economic efficiency of enterprises in the region subject to the concept of sustainable development. The scientific works of many scientists were devoted to this task [4-7]. These studies help to consider important factors of statistics of key indicators regional development of enterprises.

Modeling of the dynamics of indicators regional development of enterprises can be produced by new methods of Data mining. There are many works dedicated to use these methods to improve quality of management of enterprises on different levels: local, region, country and other [8-10].

Despite the broad theoretical and applied elaboration of sustainable development management in different socio-economic systems and at the level of the country's economy, it should be noted that there is no methodology for integrated management of sustainable development from the standpoint of a holistic approach to modeling the dynamics of such development.

The relevance of the study is based on the questions of sustainable development of enterprises, the analysis of statistic indicators of enterprises in different regions, data mining methods in researching of sustainable development enterprises of Ukraine by region. The purpose, tasks and directions of the research are determined by the insufficient development of the management level of local enterprises and organizations in sustainable development goals reaching.

\footnotetext{
* Corresponding author: maxishko@ukr.net
} 
The purpose of this article is to obtain recommendations for justification for the choice of strategies development of regional enterprises, based on results of data mining with taking into account the concept of sustainable development.

\section{Materials and methods}

The concept of sustainable development is a new approach that defines new guidelines for the world order. However, significant changes in connection with the transition to sustainable development in all spheres of public life, including political, involve the definition of new complex goals and objectives that require some transformation of this system.

If we consider sustainable development from the point of view of the social component, the agenda of social institutions includes problems related to establishing a balance between the needs of modern generations (namely, the need for global governance, finding effective ways to address pressing issues), on the one hand, and, on the other hand an efficient economic system.

Sustainable development is the process of building a state based on the coordination and harmonization of social, economic and environmental components in order to meet the needs of present and future generations. Harmony in the development of three components of the modern world: man - economy - nature is the basis of sustainable development.

On the way to sustainable development of a country or region, research of indicators that determine this development are important: social (life expectancy, level of education, sanitation, involvement of the working population); ecological (preservation of biodiversity and natural landscapes, waters, atmospheric air, use of household waste); economic (capital investment, remodeling of production, GDP per capita, development of science and technology); institutional (access to information, environmental education, public participation in addressing issues of local and national importance).

The main goal of sustainable development of Ukraine is to ensure dynamic socio-economic growth, preserve the quality of the environment and rational use of natural resource potential, meet the needs of present and future generations by building a highly efficient economic system that stimulates environmental sustainability, productive work, scientific and technological progress. and also has a social orientation.

More and more attention is paid to the practical implementation of the concept of sustainable development in the world. The aggravation of the economic, environmental and social situation requires each state to take measures so that the activities carried out on its territory are not the cause of environmental degradation, which leads to changes in the functions of the state. Hence the modern responsibilities of states:

- to preserve and to use the environment and natural resources in the interests of present and future generations;
- to support the ecosystem and ecological processes necessary for the functioning of the biosphere, to protect biological diversity and to adhere to the principles of maintaining maximum sustainability of productivity during the use of living natural resources and ecosystems;

- to establish appropriate norms of environmental protection, monitor changes in environmental quality, as well as publish all data in this regard.

Thus, the struggle for the preservation of the natural foundations of life should be included among the important state tasks. It is natural that the priority of the environmental function in a global crisis should be quite high - it needs to take place immediately after the economic, to the greatest extent to influence government decision-making.

Since the formation of the system of assessment of sustainable development of enterprises on the basis of criteria and indicators is carried out taking into account the most problematic aspects of management related to the functioning of ecosystems, environmental, economic and social needs of society, it must perform not only informational and control functions. reflect the desired changes and trends and timely direct efforts to achieve the goal.

At the international level, criteria and indicators are a tool to help:

- creation of a single database relating to the state of the economic sector of the world, their ability to perform environmental, economic and socio-cultural functions in order to solve global environmental problems that threaten the existence of mankind, as well as providing basic needs of present and future generations;

- improvement of international cooperation in order to develop common provisions, recommendations and define long-term strategies and, accordingly, to form common approaches and requirements to the system of evaluation of the country's progress towards sustainable enterprise development, including clear and uniform interpretation of terms, methods of collecting, processing, disseminating information, etc. ;

- harmonization of important aspects of international trade related to ensuring compliance with the principles of sustainable development, environmental and socioeconomic requirements for the management process.

At the national level, the application of a system of criteria and indicators will be useful for:

- control over the implementation of Ukraine's international obligations related to the decisions of the UN conventions on environment and development, as well as the provisions set out in the Concept of Sustainable Development of Ukraine and other state regulations;

- improvement of national economic, legal framework to take into account the basic requirements for sustainable use of natural resources, national priorities and environmental and economic characteristics of nature, as well as adjusting existing programs, various measures in line with economic trends;

- improvement of the decision-making process regarding the conservation, protection, reproduction and use of natural resource potential.

At the operational level of management include evaluation of the effectiveness of business, which 
coordinates the management at the operational level, as well as the formation of information base not only for management purposes and objectives, but also to improve all environmental practices in accordance with existing environmental and economic conditions, potential and new capabilities achievements in scientific and technical sphere.

Definitely, using only the system of assessment can 't provide sustainable development without new methods and models. So, to improve the achievement of goals of sustainable development its necessary use data mining.

To solve this problem is recommended to use classification and cluster analyses. Unlike classification tasks, cluster analysis does not require a priori assumptions about the data set, does not impose restrictions on the display of the studied objects, allows you to analyze indicators of different types of data (interval data, frequencies, binary data). Also, chosen variables must be measured on comparable scales.

Cluster analysis allows to reduce the dimensionality of data, to make them clear. Cluster analysis can be applied to sets of time series, here periods of similarity of some indicators can be distinguished and groups of time series with similar dynamics can be determined.

Let's define variables for cluster analysis.

To choose variables for clustering lets analyze indicators of entrepreneurship development (Fig. 1).

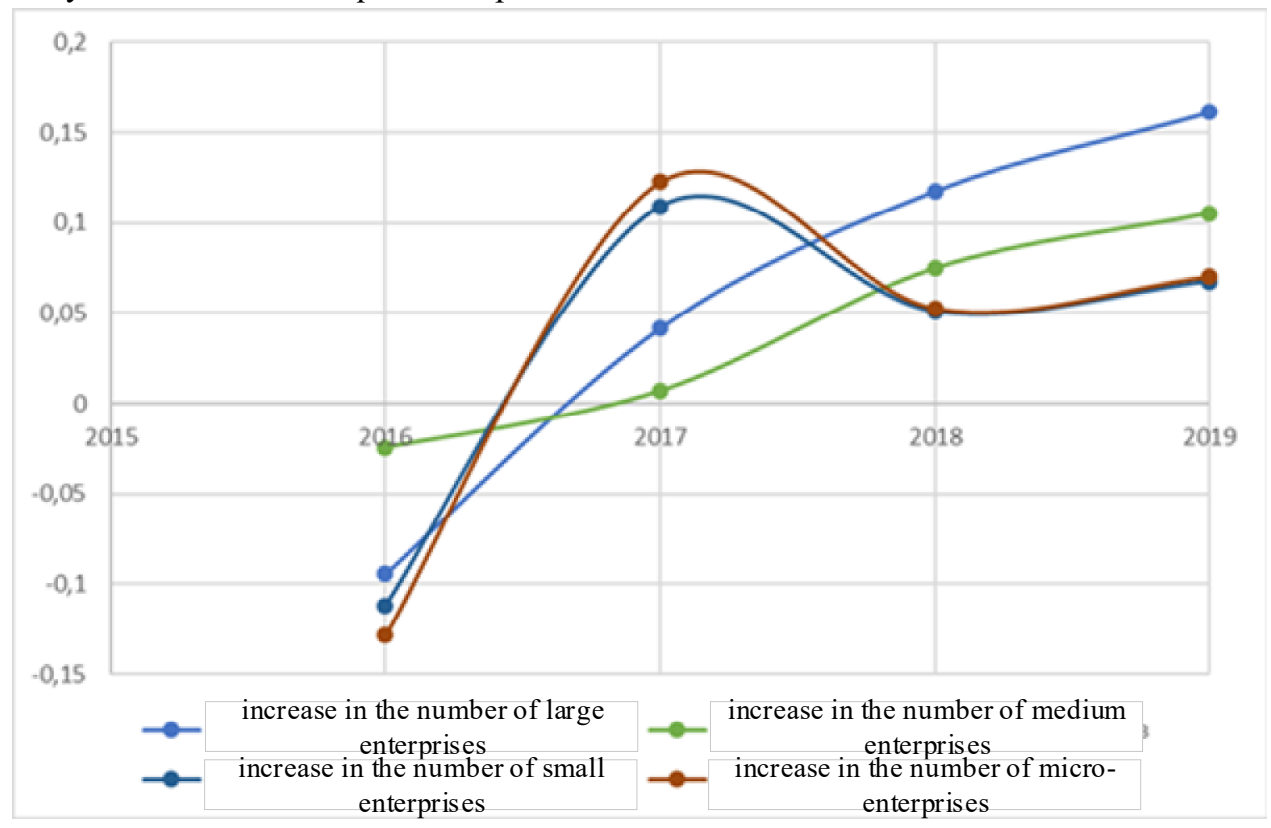

Fig. 1. Increases in the number of enterprises by type in the period from 2015 to 2019 [11].

One of the important indicators of business development, which determines the favorable business environment in particular and the state of the economy as a whole, is the number of small and micro enterprises. A feature of the development of domestic entrepreneurship is a significant jump in the number of small and micro enterprises, caused by the adoption in 2016 of the "Strategy for the development of small and medium enterprises in Ukraine until 2020."

There are 380597 enterprises in Ukraine with net profit about 523778 UAH million according to state statistics service of Ukraine [11]. Due to the analysis of enterprises development, seven variables were chosen for clustering from the full number of 62 , which can fully characterize directions of the sustainable development.

In the analysis we will consider the following objects: Vinnytsia, Volyn, Dnipropetrovsk, Zhytomyr, Zakarpattia, Zaporizhzhia, Ivano-Frankivsk, Kyiv, Kirovohrad, Lviv, Mykolaiv, Odessa, Poltava, Rivne, Sumy, Ternopil, Kharkiv, Khmelnytsky, Cherkasy, Chernivtsi, Chernihiv regions.

As variables for clustering we will use the parameters that characterize directions of the sustainable development of the region:
1 - economic direction:

- quantity of sold products by regions;

- the number of employees in business entities by region;

2 - social direction:

- staff costs of enterprises by region;

- capital investments in environmental protection by regions;

3 - ecological direction:

- current costs of environmental protection by region;

- carbon dioxide emissions by region;

- emissions of pollutants into the atmosphere from stationary sources of pollution by region.

The process of ensuring the sustainable development of the enterprise involves the solution of a significant number of complex tasks, among which a lot of space is occupied by the processes of evaluation and implementation. The main task in the study of development is to identify for a particular enterprise all the opportunities that can be used.

To analyze the sustainable development of Ukraine by region, we will use statistics for 2015-2019 (2020 will not be used due to the significant impact of the pandemic, which significantly affected these parameters) [11]. 
Among the indicators of the dynamics of these parameters we will use the following.

Average time series value:

$$
X_{c p}=\frac{\sum_{i}^{n} X_{i}}{n}
$$

where $X_{i}$ is the value of the indicator at period $i, n$ is the total number of periods.

Standard deviation (RMS):

$$
X_{C K O}=\sqrt{\frac{\sum_{i}^{n}\left(X_{i}-\bar{X}\right)}{n}}
$$

where $\bar{X}$ is the average value of the indicator.

The value of time series growth for 2015-2019:

$$
X_{\mathrm{p}}=X_{2019}-X_{2015}
$$

where $X_{2019}, X_{2015}$ values of indicators in the specified periods.

The main point of the study is the choice of distance, this distance depends on the options for the final partition. The most common are two procedures: the method of "nearest neighbor" and the method of "far neighbor".

The criterion for determining the similarities and differences of clusters is the distance between the points on the scattering diagram. This similarity can be "measured", it is equal to the distance between the points on the graph. There are few ways to determine the degree of distance between clusters, which is also called the degree of proximity. The most common way is to calculate the Euclidean distance between two points $i$ and $\mathrm{j}$ on a plane when their $\mathrm{X}$ and $\mathrm{Y}$ coordinates are known. Therefore, in paper there is used Euclidean distance for cluster analysis.

If we need to find the distance between two points in the space of a larger number of measurements, the formula changes to the number of specified measurements.

To perform cluster analysis, we use the MS Excel toolkit add-on Data Mining.

\section{Results}

We use the tools to search for categories of Analysis Services by the above indicators (Table 1). To search for categories, use the value of the searched categories -3 .

Table 1. The total number of objects in the clusters.

\begin{tabular}{|c|c|}
\hline Category name & Row counter \\
\hline Cluster 1 & 12 \\
\hline Cluster 2 & 5 \\
\hline Cluster 3 & 5 \\
\hline
\end{tabular}

Thus, we obtain three clusters. Cluster 1 has the largest number of facilities, including Volyn, Zhytomyr, Zakarpattia, Kirovohrad, Mykolaiv, Rivne, Sumy, Ternopil, Kherson, Khmelnytsky, Chernivtsi and Chernihiv regions. This cluster is characterized by the following characteristics (Table 2).

According to this analysis, the following conclusions can be drawn: the first category includes regions with low levels of harmful emissions and personnel costs. These are regions without developed industry with moderate costs of enterprises to support workers. Significant changes in the number of employees involved in the enterprise are constantly increasing.

Let's analyze cluster 2. This cluster includes such regions as Dnipropetrovsk, Zaporizhzhia, Kyiv, Poltava, Kharkiv regions.

The second cluster is characterized by the following characteristics (Table 3). According to the results of the cluster analysis, this group includes regions with a moderate level of emissions of toxic substances and an increase in current expenditures on environmental protection. However, the environmental costs themselves in this cluster are higher than in other clusters. This cluster is represented by regions with developed industry.

It can be concluded that with a significant increase in emissions of substances High level of growth of carbon emissions: $11118,3964094464-35759,6843737088$, the cost of improving the environmental situation is not significant.

Table 2. Characteristics of the cluster 1.

\begin{tabular}{|c|c|c|}
\hline Column & Value & The importance (\%) \\
\hline Standard deviation of carbon emissions & Low: $<652,3916407808$ & 100 \\
\hline Average values of staff & Low: $<8850140,26319299$ & 96 \\
\hline Average values of products & Very low: $<99659768,2879332$ & 82 \\
\hline Average values of emissions of substances & Low: $<59,2431839616$ & 81 \\
\hline Standard deviation of values of staff & Low: $<3912059,98129316$ & 79 \\
\hline Average values of carbon emissions & Low $:<3486,4703696896$ & 62 \\
\hline Growth of investment & Low: $<118108,007038976$ & 61 \\
\hline
\end{tabular}

Table 3. Characteristics of the cluster 2.

\begin{tabular}{|c|c|c|}
\hline Column & Value & The importance (\%) \\
\hline Standard deviation of emissions of substances & Average:33,5023949444-163,1016636416 & 35 \\
\hline Growth of environmental costs & Average:739425,918124032-1987735,51220654 & 33 \\
\hline Standard deviation of investment & Average:90005,5426793472-676550,476719718 & 28 \\
\hline Standard deviation of environmental costs & High:>=516068,619426202 & 27 \\
\hline Average values of environmental costs & High:636797,562493338-2291954,27998597 & 27 \\
\hline Average values of investment & Average: $184307,307380736-714445,43874007$ & 27 \\
\hline
\end{tabular}


Let's analyze cluster 3 . This cluster includes such regions as Vinnytsia, Ivano-Frankivsk, Lviv, Odessa, Cherkasy regions.
The second cluster is characterized by the following characteristics (table 4).

Table 4. Characteristics of the cluster 3

\begin{tabular}{|c|c|c|}
\hline Column & Value & The importance (\%) \\
\hline Standard deviation of carbon emissions & Average:652,3916407808-6697,0645192704 & 100 \\
\hline Growth of emissions of substances & Very High: $>=-4,4394651672$ & 55 \\
\hline Average values of products & Low:99659768,2879332-210243602,310234 & 49 \\
\hline Average values of emissions of substances & Average:59,2431839616-629,3593749504 & 32 \\
\hline Average values of values of staff & Average: $8850140,26319299-19665719,2475034$ & 31 \\
\hline Growth of values of staff & Average: $16272684,5190504-26496168,0780296$ & 26 \\
\hline
\end{tabular}

According to clustering data, this class includes regions with average values of harmful emissions and low growth of environmental costs. Unlike other clusters, the objects of this show a very high level of pollution growth with a low value of the products produced by enterprises. These areas are mainly aimed at the recreational sector and tourism without significant industrial facilities. The growth of emissions is largely due to the development of the economy and the emergence of new enterprises during the period under review.

The results of the analysis can be seen in Fig. 2, which shows the ratio of low, medium, high and very high levels of growth in emissions, environmental costs and production by category.

Thus, we can conclude that the regions with developed industry (cluster 2) show the largest increase in the cost of improving the quality of the environment. Also, cluster 3 is characterized by a significant increase in the number of manufactured products and an increase in harmful emissions with a consistently small contribution to the maintenance of the environment.

According to the results of the cluster analysis, three groups of regions have been identified for which it is advisable to apply different types of strategies to implement the concept of sustainable development.

There is no doubt that due to a number of differences in the sustainable development of enterprises in different regions, it is necessary to apply different strategies for the integration of the concept.

In general, based on the resolution of the Verkhovna Rada of Ukraine on the Concept of Sustainable Development in Settlements, it is planned to improve the current state of development in the following areas: coordination of social, economic, urban and environmental aspects of development of settlements and surrounding areas., creating appropriate conditions for the development of enterprises of all forms of ownership for productive employment, restoration of human and scientific potential, a sufficient number of jobs and others.

To do this, a number of measures are planned to:

- ensuring the rational use of natural resources;

- improving the social living conditions of the population;

- providing the population with housing;

- improvement of production infrastructure;

- development of transport infrastructure;

- development of engineering infrastructure;

- formation of a full-fledged living environment in settlements;

- improvement of sanitary and hygienic conditions;
- protection from adverse natural phenomena;

- prevention of man-made accidents.

However, the funds of local enterprises and organizations of all forms of ownership, capital investments of the state and local budgets are used for the implementation of the measures [12]. Therefore, it is necessary to identify those measures that will bring the greatest benefit within the concept of sustainable development for the region.

Based on the cluster analysis, we offer recommendations for the selection of priority measures by region (Table 5).

These recommendations identify priority actions for areas that need more attention. The application of the stated priorities will allow to carry out actions to achieve the concept of sustainable development more effectively.

The application of the recommendations will allow on the basis of a more efficient allocation of resources to enable the following tasks, which were established in [13]:

- to ensure the annual growth of gross domestic product;

- to promote a change in the structure of exports towards the growth of products and services with a high share of value added;

- to achieve productivity growth in the economy through diversification, technical modernization, creating incentives, including tax incentives, for innovation and increasing the number of jobs.

\section{Conclusion}

The peculiarity of the functioning of enterprises in the current conditions of a long crisis is their constant dependence on the whole set of industrial and nonindustrial entities, which is characterized by increased fierce competition. As a result, it negatively affects the competitiveness and sustainability of domestic enterprises. Therefore, the main task of the enterprise in modern economic conditions is to solve the problem of sustainable development and the ability to withstand adverse situations.

The using of the main socio-economic indicators to get sustainable development in the international, the national and the operational levels was analyzed.

The sustainable development of Ukrainian enterprises is analyzed, on the basis of which the main factors of 
restoration of the main socio-economic indicators of Ukrainian enterprises are chosen.

A cluster analysis of the dynamics of sustainable development of Ukrainian enterprises by regions is constructed. Based on clustering, the regions were divided into three groups. A detailed analysis of each of the groups of regions was conducted.

On the basis of cluster analysis, recommendations are proposed on priority measures to increase the level of sustainable development of Ukraine, which allows improve quality of citizens' life and reach economic development.

The obtained results can be used in the development of funds of local enterprises and organizations to improve the efficiency of the allocation of resources, which will increase the quality of achieving sustainable development goals.

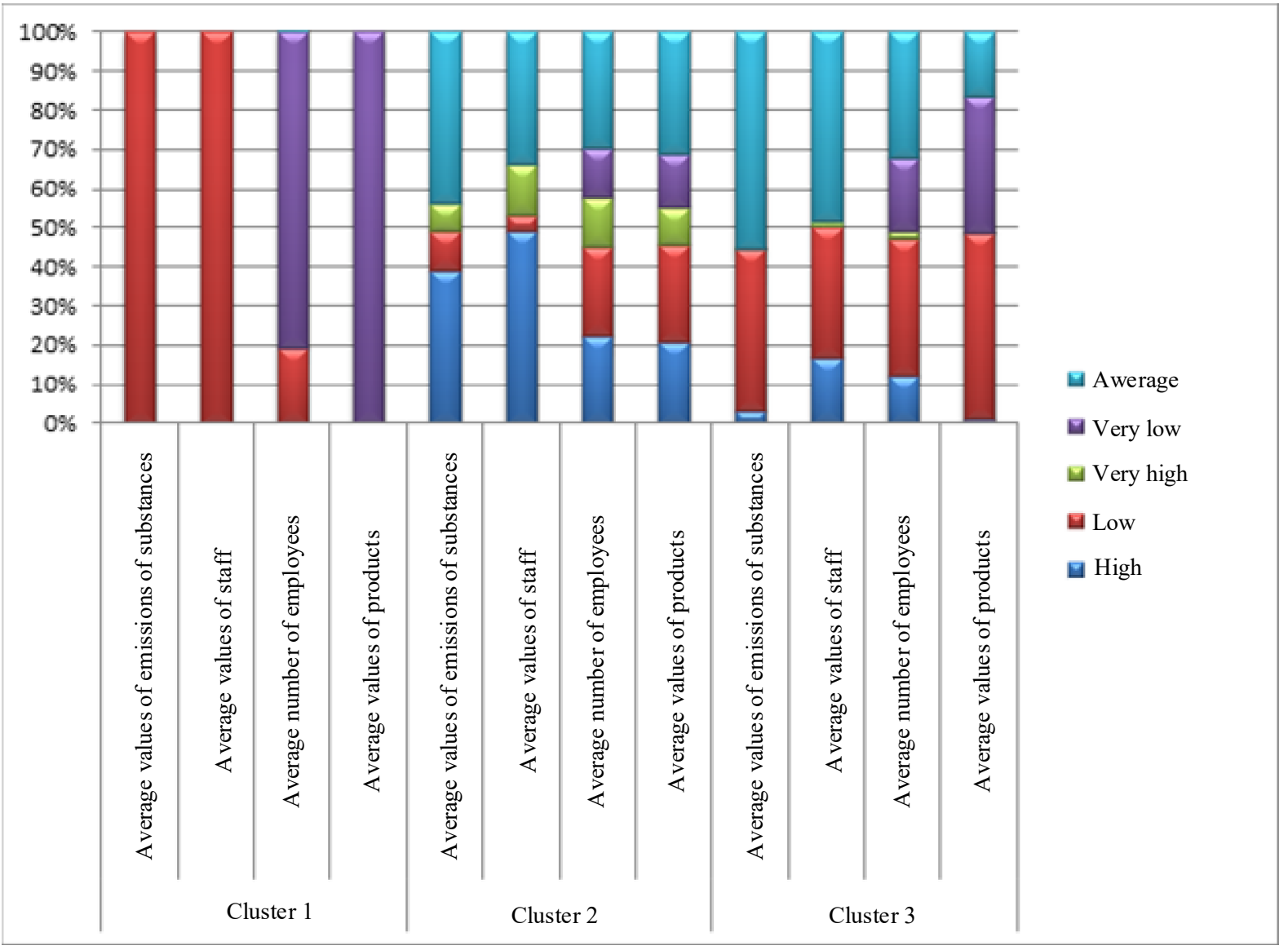

Fig. 2. The results of cluster analysis.

Table 5. Recommendations for measures to achieve the concept of sustainable development by region.

\begin{tabular}{|c|c|l|}
\hline Cluster & Regions included in the cluster & \multicolumn{1}{c|}{ Recommended measures } \\
\hline 1 & $\begin{array}{c}\text { Volyn, Zhytomyr, Zakarpattia, Kirovohrad, Mykolaiv, } \\
\text { Rivne, Sumy, Ternopil, Kherson, Khmelnytsky, Chernivtsi } \\
\text { and Chernihiv regions }\end{array}$ & $\begin{array}{l}\text { a) ensuring the rational use of natural resources; } \\
\text { b) improvement of production infrastructure; } \\
\text { c) improving the social living conditions of the population. }\end{array}$ \\
\hline 2 & $\begin{array}{r}\text { Dnipropetrovsk, Donetsk, Zaporizhzhia, Kyiv, Luhansk, } \\
\text { Poltava, Kharkiv regions }\end{array}$ & $\begin{array}{l}\text { a) improving the social living conditions of the population; } \\
\text { b) improvement of sanitary and hygienic conditions; } \\
\text { c) prevention of man-made accidents. }\end{array}$ \\
\hline 3 & $\begin{array}{l}\text { Vinnytsia, Ivano-Frankivsk, Lviv, Odessa, Cherkasy regions } \\
\text { b) improvement of production infrastructure; } \\
\text { c) the formation of a full-fledged living environment in } \\
\text { settlements. }\end{array}$ \\
\hline
\end{tabular}

\section{References}

1. R. Emas, The Concept of Sustainable Development: Definition and Defining Principles. Brief for GSDR (2015). doi:10.13140/RG.2.2.34980.22404.
2. T. Klarin, The Concept of Sustainable Development: From its Beginning to the Contemporary. ZIREB 21(1), 67-94 (2018). doi:10.2478/zireb-2018-0005.

3. D. Brechko, N. Maksyshko, S. Ivanov, Development of Elements of ERP-system of Association of Coowners of Multi-apartment, in 10th International Conference on Advanced Computer Information 
Technologies (ACIT), Deggendorf, Germany, 567572 (2020). doi: 10.1109/ACIT49673.2020.9208962.

4. D. Ocheretin, V. Los, H. Kucherova, O. Bilska, An alternative approach to modeling the country's business climate in conditions of limited information. E3S Web of Conf. 166, 13024 (2020). doi:10.1051/e3sconf/202016613024.

5. W. Sobczyk, Probl. of sust. devel. 9 (1), 119-126 (2014).

6. Tuan-Anh Nguyen Pham, Xutao Li, Gao Cong, A General Model for Out-of-town Region Recommendation, in Proc. of the 26th Inter. Conf. on $W W W$. 17, 401-410 (2017). doi:10.1145/3038912.3052667.

7. F. Amato , B. A. Maimone, F. Martellozzo, G. Nolè, B. Murgante, The Effects of Urban Policies on the Development of Urban Areas. Sustainability 8 (4), 297 (2016). doi:10.3390/su8040297.

8. C. Kleissner, Data mining for the Enterprise. IEEE Proc. 31 Annual Hawaii International Conference on System Sciences 7, 295-304 (1998). doi:10.1109/HICSS.1998.649224.

9. A. Ramachandra Rao, V. V. Srinivas Regionalization of watersheds by fuzzy cluster analysis. J. of Hyd. $318 \quad 57-79 \quad$ (2006). doi:10.1016/j.jhydrol.2005.06.004.

10. J. Feser, M. Bergman, National Industry Cluster Templates: A Framework for Applied Regional Cluster Analysis. Reg. Stud. 34, 1-19 (2000). doi:10.1080/00343400050005844.

11. State statistics service of Ukraine Knowledgebase (State Statistics Service of Ukraine, Kyiv, 2020), http://www.ukrstat.gov.ua/. Accessed 25 December 2020

12. About the Goals of sustainable development of Ukraine for the period up to 2030 (Verkhovna Rada of Ukraine Legislation of Ukraine, 2020), https://zakon.rada.gov.ua/laws/show/722/2019\#Text . Accessed 12 December 2020.

13. About the Strategy for Sustainable Development of Ukraine until 2030 (Main legal portal of Ukraine, 2020), http://search.ligazakon.ua/__doc2.nsf/link1/J H6YF00I.html. Accessed 12 December 2020. 